\title{
Impact of analyzing fewer image frames per segment during offline volumetric radiofrequency-based intravascular ultrasound measurements of target lesions prior to percutaneous coronary interventions
}

\author{
Jennifer Huisman • Marc Hartmann • Gary S. Mintz • \\ Gert K. van Houwelingen - Martin G. Stoel • Frits H. A. F. de Man • \\ Hans W. Louwerenburg · Clemens von Birgelen
}

Received: 25 October 2010/Accepted: 2 March 2011/Published online: 19 March 2011

(C) The Author(s) 2011. This article is published with open access at Springerlink.com

\begin{abstract}
In the present study, we evaluated the impact of a 50\% reduction in number of image frames (every second frame) on the analysis time and variability of offline volumetric radiofrequency-based intravascular ultrasound (RF-IVUS) measurements in target lesions prior to percutaneous coronary interventions (PCI). Volumetric RF-IVUS data of vessel geometry and plaque composition are generally obtained by a semi-automated analysis process that includes timeconsuming manual contour editing. A reduction in the number of frames used for volumetric analysis may speed up the analysis, but could increase measurement variability. We repeatedly performed offline volumetric analyses in RF-IVUS image sets of $20 \mathrm{~mm}$-long coronary segments that contained 30 de novo lesions prior to PCI. A 50\% reduction in frames decreased the
\end{abstract}

J. Huisman · M. Hartmann · G. K. van Houwelingen ·

M. G. Stoel · F. H. A. F. de Man .

H. W. Louwerenburg · C. von Birgelen $(\square)$

Department of Cardiology, Thoraxcentrum Twente,

Medisch Spectrum Twente, Haaksbergerstraat 55,

7513 ER Enschede, The Netherlands

e-mail: c.vonbirgelen@mst.nl

G. S. Mintz

Cardiovascular Research Foundation, New York, NY, USA

C. von Birgelen

MIRA, Institute for Biomedical Technology

and Technical Medicine, University of Twente,

Enschede, The Netherlands analysis time significantly (from $57.5 \pm 7.3$ to $35.7 \pm$ $3.7 \mathrm{~min} ; P<0.0001)$ while geometric and compositional RF-IVUS measurements did not differ significantly from measurements obtained from all frames. The variability between measurements on the reduced number of frames versus all frames was comparable to the intra-observer measurement variability. In target lesions prior to PCI, offline volumetric RF-IVUS analyses can be performed using a reduced number of image frames (every second frame). This reduces the time of analysis without substantially increasing measurement variability.

Keywords Coronary artery disease - Intravascular ultrasound · Radiofrequency · Virtual histology · Plaque composition · Frame density · IVUS . VH-IVUS · Reproducibility · Variability · Atherosclerosis
Abbreviations
IVUS Intravascular ultrasound
PCI Percutaneous coronary interventions
RF Radiofrequency
TCFA Thin cap fibroatheroma

\section{Introduction}

While conventional greyscale intravascular ultrasound (IVUS) is a tomographic invasive imaging technique that permits accurate quantification of vessel and 
plaque dimensions and a limited assessment of plaque composition [1-3], radiofrequency-based IVUS (RFIVUS) allows a more advanced assessment of plaque composition [3-5]. By use of motorized pullbacks of the IVUS catheter, it is possible to perform accurate volumetric measurements [6-9]. Therefore, volumetric RF-IVUS is increasingly used for the assessment of coronary atherosclerosis and the direct and longterm effects of percutaneous coronary interventions (PCI) [10-16].

RF-IVUS systems comprise a semi-automated contour detection program by which the vessel and lumen boundaries are automatically traced on each cross-sectional image frame of a coronary segment. In a subsequent (and relatively time consuming) process these automatically-detected contours are visually checked and, if required, corrected by computerassisted manual editing by an experienced analyst in order to generate reliable volumetric RF-IVUS data [17-19]. Generally, such corrections are required in the majority of IVUS frames [19]. As previously demonstrated in much milder coronary disease, a $50 \%$ reduction of cross-sectional image frames used to generate the volumetric RF-IVUS data can significantly reduce analysis time [19]. However, this approach resulted in a substantial increase in measurement variability for some tissue components such as necrotic core [19]. Theoretically, in more advanced atherosclerotic lesions such a reduced number of frames could have less impact on volumetric RF-IVUS measurements. Therefore, we evaluated the impact of reducing the number of cross-sectional IVUS image frames used to generate RF-IVUS volumetric data during offline analysis of target lesions prior to PCI on measurement variability.

\section{Methods}

Study population

IVUS image sequences were obtained in 30 patients with symptomatic coronary artery disease who were in sinus rhythm and scheduled for PCI procedures or de novo lesions. IVUS was performed prior to any intervention. As in previous studies [17, 19-21] we did not study coronary segments with major side branches, severe calcification (total arc of calcium $>180^{\circ}$ and/or any single arc of calcium deposits $>75^{\circ}$, in each cross-sectional image frame) or extreme vessel tortuousity (based on the operators' visual assessment of the angiogram) that could have limited quantitative assessment of vessel borders. Informed consent was obtained prior to cardiac catheterization from all patients in accordance with the directives of the Local Medical Ethics Committee.

\section{RF-IVUS data acquisition}

RF-IVUS data were acquired with commercially available phased-array IVUS catheters (Eagle Eye GoldTM $20 \mathrm{MHz}$, Volcano Corporation, Rancho Cordova, CA, USA) by a dedicated console (InVision GoldTM Volcano Corporation). The IVUS catheter probe was placed $\geq 10 \mathrm{~mm}$ distal to the most distal side-branch; angiographic cine runs were performed to define the position of the IVUS catheter. After intracoronary injection of $200 \mu \mathrm{g}$ nitroglycerin, a continuous pullback of the IVUS catheter was performed using a motorized pullback device at $0.5 \mathrm{~mm} / \mathrm{s}$ (TrackBack-II, Volcano Corporation); during the pullback greyscale images were recorded and in an ECG-gated manner (i.e., at the top of the R-wave) raw RF-data were acquired [22]. IVUS image data were stored on digital video disk for offline analysis.

A detailed description of the technique and validation of RF-IVUS has previously been reported $[4,5,7]$. In brief, spectral (raw) IVUS RF-data were reconstructed to generate tissue maps in order to classify and display the plaque in four major components: fibrous (green); fibro-lipidic (light-green); necrotic core (red); and calcium (white).

\section{RF-IVUS image analysis}

RF-IVUS analysis of the coronary segments was performed offline by an experienced IVUS analyst. Twenty-millimeter-long coronary segments, located between two adjacent side-branches, were analyzed. By using a semi-automated contour detection program (Volcano pcVH software program version 2.2 by Volcano Therapeutics Inc., USA), vessel and lumen borders were automatically traced. The leading edge of the media-adventitia interface and the leading edge of the blood-intima acoustic interface were used for definition of vessel and lumen borders, respectively. The automatically detected vessel and lumen borders of each cross-sectional image were visually 
checked and, if required, contours were corrected by computer-assisted manual editing. Plaque+media (Plaque) area was used as a measure of atherosclerotic plaque and was calculated as the difference between vessel and lumen cross-sectional area (plaque area $=$ vessel area - lumen area) [3].

For each coronary segment, volumetric data of vessel, lumen and plaque volume and plaque burden as well as absolute and relative amounts of fibrous, fibro-lipidic, necrotic core, and calcified tissue were obtained from the application of the trapezium method to the cross-sectional area measurements. The trapezium method is derived from the Simpson's rule method, but takes the accurate distances between adjacent image frames into account [18, 19]. The pcVH software program uses this method to calculate volumes from the cross-sectional area data. Volumetric plaque burden (\%) was calculated as (plaque volume/vessel volume) $\times 100 \%$. To account for any differences in lengths, all volumetric data were normalized for $10 \mathrm{~mm}$-long segments [11].

\section{RF-IVUS data analysis}

Volumetric geometrical and compositional IVUS data were obtained from three different analyses [19], each performed on all 30 coronary segments, to obtain insight into the effect of reducing the number of cross-sectional image frames used for the generation of volumetric data (Fig. 1). Analyses were spread over a period of 3 months, and the IVUS analyst was blinded to the results of previous analyses. Analysis time (time from start of manual contour editing to calculation of volumetric data) was recorded for the different approaches.

In order to generate volumetric data, automated contour detection was performed with the $\mathrm{pcVH}$ software on all image frames followed by a visual check and manual contour editing which was required on almost every cross-sectional image frame (Analysis I). This analysis was performed a second time (Analysis II) to assess the intra-observer variability. In the third analysis following the automated contour detection (on all image frames), the contours of every second frame were skipped by use of the IVUS analysis software (i.e., no check or editing of contours that were not used for any calculation). Manual contour editing of this reduced number of image frames (50\% of total frames) was performed in order to generate new volumetric data (Analysis III). Thus, Analysis III involved a manual contour editing step that was potentially more difficult as a result of the reduced number of cross-sectional image frames (larger "steps" between image frames) [19].

\section{Statistical analysis}

Statistical analyses were performed with SPSS 15.0 (SPSS Inc., Chicago, IL, USA). Quantitative data are presented as mean $\pm 1 \mathrm{SD}$ and compared using student's $t$ test. Differences between analyses were presented as mean \pm 1 SEM. A two-sided $P$ value $<0.05$ was considered as significant. According to Bland and Altman, the agreement between two measurements was assessed by determining the mean $\pm 2 \mathrm{SD}$ of the between measurement differences [23]. Intra-class correlations were calculated for comparisons at individual level. An intraclass correlation $>0.90$ was considered good. The frequency of RF-TCFA was compared using cross-tables.

\section{Results}

Study population and RF-IVUS data

In 30 patients ( 23 men; $62 \pm 10$ years of age) with stable angina, a total of 30 de novo coronary lesions were examined with RF-IVUS prior to PCI (10 RCA; 12 LAD; 8 LCX). The mean heart rate during IVUS examination was $64 \pm 11 \mathrm{bpm}$. There was no complication related to IVUS imaging.

A total of 3,725 IVUS cross-sections were analyzed: $49 \pm 11$ frames/segment for Analysis I and II based on all image frames, and $25 \pm 6$ frames/ segment for Analysis III based on the reduced number of image frames. The vast majority of image frames $(\geq 95 \%)$ had to be edited in order to generate accurate measurements. The length of the segments measured $20.0 \pm 0.2 \mathrm{~mm}$ (range 19.5-20.4 mm) with a plaque burden of $53.0 \pm 9.5 \%$ (range 36-71\%). The atherosclerotic segments contained pre-dominantly fibrous tissue $(53.7 \pm 9.4 \%)$ and necrotic core $(22.8 \pm 7.1 \%)$. The mean distance between consecutive frames was $0.4 \pm 0.1 \mathrm{~mm}$ (range $0.2-0.6 \mathrm{~mm}$ ) for Analyses I and II, and $0.9 \pm 0.2 \mathrm{~mm}$ (range $0.5-1.3 \mathrm{~mm}$ ) for Analyses III. Table 1 presents the complete set of volumetric RF-IVUS data. 
Fig. 1 Different ways of RF-IVUS data analysis and generation of volumetric data. In Analysis I and II automated contour detection with (visual check and) manual contour editing was performed on every cross-sectional image frame. In Analysis III, following the automated contour detection performed on all image frames by the pcVH software, the contours of every second frame were skipped (i.e., no check or editing of these contours that were not used for any calculation). Manual contour editing of this reduced number of image frames was then performed in order to generate new volumetric data [19]

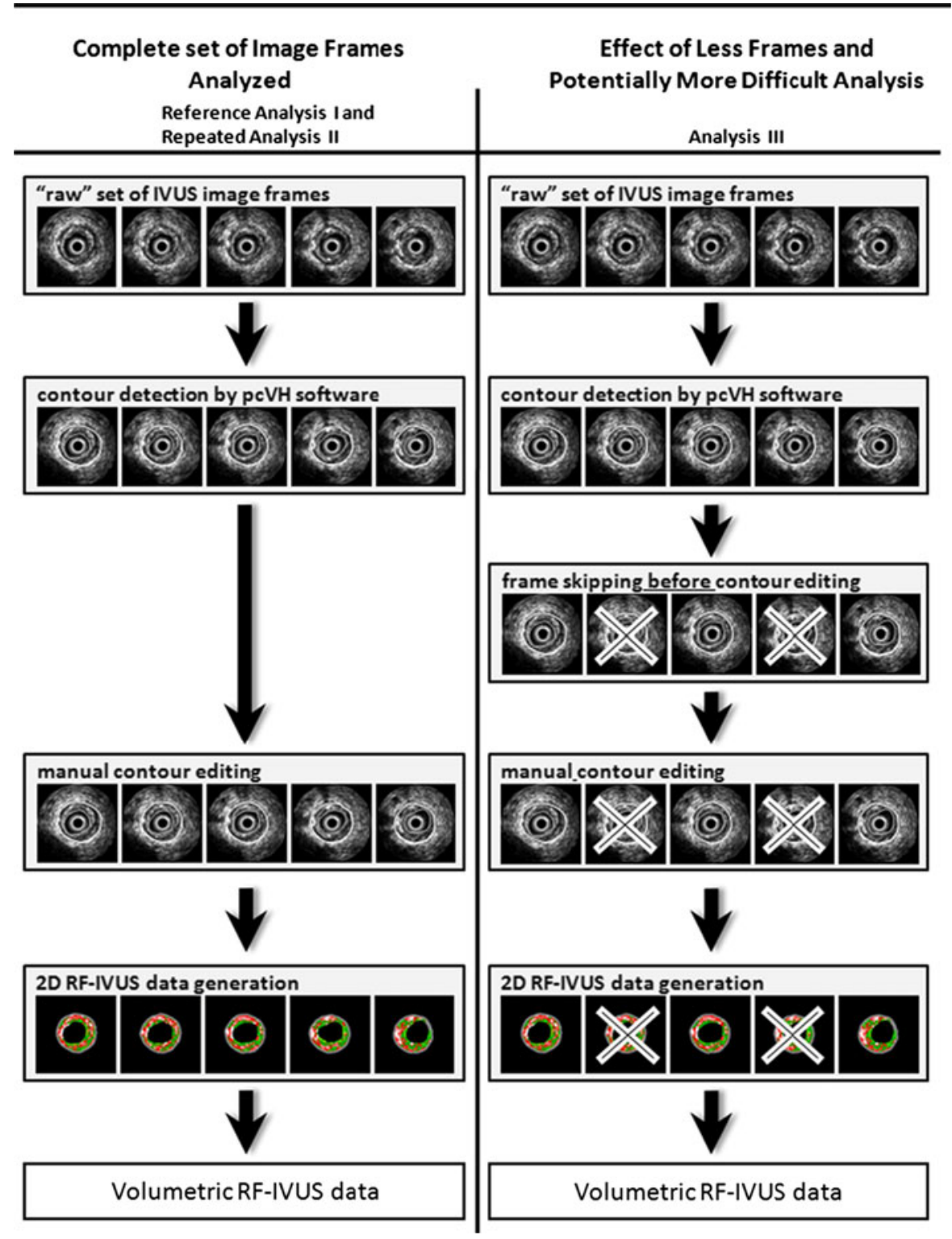

Intra-observer comparison and measurement variability

Comparing Analysis I to Analysis II showed little intra-observer variability for geometric as well as compositional data (Table 2) with excellent intraclass correlations (all $\geq 0.95$ ). Intra-observer comparison showed no significant differences for geometric measurements (relative differences $<1.5 \%$; Table 2). In addition, absolute and relative compositional data showed no significant differences (relative differences for plaque composition $<4 \%$; Table 2). The limits of agreement were relatively small for both geometry and plaque composition (Figs. 2, 3).

Reduced number of frames and measurement variability

Generation of volumetric RF-IVUS data from a reduced number of image frames (requiring contour editing of fewer images) significantly reduced the time of analysis $(57.5 \pm 7.3$ vs. $35.7 \pm 3.7 \mathrm{~min}$; 
Table 1 IVUS data of three different ways of RFIVUS analysis
Values are normalized to $10 \mathrm{~mm}$ length; mean \pm standard deviation

\begin{tabular}{lccc}
\hline & $\begin{array}{l}\text { Analyses I } \\
\text { Reference }\end{array}$ & $\begin{array}{l}\text { Analyses II } \\
\text { Intra-observer re-analysis } \\
\text { based on complete data } \\
\text { set of all frames }\end{array}$ & $\begin{array}{l}\text { Analysis III } \\
\text { Reduced number of } \\
\text { frames (and potentially } \\
\text { more difficult analysis) }\end{array}$ \\
\hline Vessel geometry & & & \\
Vessel volume $\left(\mathrm{mm}^{3}\right)$ & $151.3 \pm 43.9$ & $152.3 \pm 43.4$ & $151.3 \pm 43.6$ \\
Lumen volume $\left(\mathrm{mm}^{3}\right)$ & $69.5 \pm 21.0$ & $70.6 \pm 22.0$ & $70.0 \pm 21.6$ \\
Plaque volume $\left(\mathrm{mm}^{3}\right)$ & $81.8 \pm 31.9$ & $81.7 \pm 29.7$ & $81.3 \pm 29.9$ \\
Plaque burden $(\%)$ & $53.0 \pm 9.5$ & $52.9 \pm 8.5$ & $53.0 \pm 8.4$ \\
& & & $25.2 \pm 14.2$ \\
Plaque composition & $25.2 \pm 15.1$ & $24.9 \pm 14.1$ & $54.3 \pm 9.0$ \\
Fibrous volume $\left(\mathrm{mm}^{3}\right)$ & $53.7 \pm 9.4$ & $53.9 \pm 8.9$ & $4.6 \pm 3.7$ \\
Fibrous volume $(\%)$ & $4.6 \pm 4.0$ & $4.6 \pm 3.7$ & $9.2 \pm 5.5$ \\
Fibro-lipidic volume $\left(\mathrm{mm}^{3}\right)$ & $9.2 \pm 5.8$ & $9.6 \pm 5.6$ & $11.1 \pm 8.1$ \\
Fibro-lipidic volume $(\%)$ & $11.2 \pm 8.6$ & $11.0 \pm 8.2$ & $22.8 \pm 6.9$ \\
Necrotic core volume $\left(\mathrm{mm}^{3}\right)$ & $22.8 \pm 7.1$ & $22.5 \pm 6.9$ & $6.0 \pm 4.5$ \\
Necrotic core volume $(\%)$ & $6.1 \pm 4.7$ & $6.0 \pm 4.5$ & $13.7 \pm 6.7$ \\
Calcium volume $\left(\mathrm{mm}^{3}\right)$ & $14.3 \pm 7.6$ & $14.0 \pm 6.9$ & \\
Calcium volume $(\%)$ & & & \\
\hline
\end{tabular}

$P<0.0001)$. In addition, it resulted in small and insignificant differences for volumetric geometric and compositional measurements when compared to measurements based on all image frames (Analysis I vs. III, relative differences $<5 \%$; Table 2 and Figs. 2,3). These differences were comparable to the intra-observer variability (Analysis I vs. II). Between Analysis I and Analysis III, there were high intraclass correlations (all $\geq 0.96$ ). Bland-Altman plots showed relative small limits of agreement (Figs. 2, $3)$.

\section{Discussion}

In the present study, we evaluated the impact of reducing the number of cross-sectional IVUS image frames for the offline calculation of RF-IVUS based volumetric data in target segments of lesions prior to PCI. The main finding of this study was that reducing the number of image frames by ignoring every second frame resulted in a significant reduction of analysis time without major impact on volumetric geometric and compositional RF-IVUS measurements. In fact, differences between volumetric analyses based on the reduced number of image frames versus analyses based on all image frames were comparable to the levels of intra-observer differences.

Previous studies on measurement variability of RF-IVUS

Rodriguez-Granillo et al. [21] first assessed the intercatheter and inter-observer variability of cross-sectional area measurements with RF-IVUS in 16 mild coronary plaques. Prasad et al. [20] examined the betweenpullback variability of RF-IVUS measurements in 16 coronary lesions prior to $\mathrm{PCI}$ with a mean plaque burden of 55\% to demonstrate that the differences between RFIVUS analyses of repeated pullbacks were lower for volumetric measurements than for cross-sectional measurements. Hartmann et al. [17] also reported in 33 mildly diseased coronary segments with a mean plaque burden of 36\% a high intra- and inter-observer reproducibility (same pullback) of volumetric RF-IVUS measurements. The findings of these studies emphasize that volumetric RF-IVUS measurements show a lower variability than cross-sectional area measurements $[17,20]$. Similar to the findings of these RF-IVUS studies, conventional (grey-scale) IVUS studies previously demonstrated a particularly low measurement variability of volumetric parameters [24, 25]. 
Table 2 Measurement differences of RF-IVUS data derived from different methods of analysis
Values are normalized to $10 \mathrm{~mm}$ length; * 2-sided student $t$ test; mean \pm standard error of the mean

\begin{tabular}{|c|c|c|}
\hline & \multicolumn{2}{|l|}{ Analyses I versus* } \\
\hline & $\begin{array}{l}\text { Analyses II } \\
\text { Intra-observer re-analysis } \\
\text { based on complete data } \\
\text { set of all frames }\end{array}$ & $\begin{array}{l}\text { Analysis III } \\
\text { Reduced number of frames } \\
\text { (and potentially more } \\
\text { difficult analysis) }\end{array}$ \\
\hline \multicolumn{3}{|l|}{ Vessel geometry } \\
\hline$\Delta$ Vessel volume $\left(\mathrm{mm}^{3}\right)$ & $\begin{array}{l}-0.98 \pm 0.90 \\
P=0.3\end{array}$ & $\begin{array}{l}-0.04 \pm 0.70 \\
P=1.0\end{array}$ \\
\hline$\Delta$ Lumen volume $\left(\mathrm{mm}^{3}\right)$ & $\begin{array}{l}-1.07 \pm 0.55 \\
P=0.1\end{array}$ & $\begin{array}{l}-0.48 \pm 0.66 \\
P=0.5\end{array}$ \\
\hline$\Delta$ Plaque volume $\left(\mathrm{mm}^{3}\right)$ & $\begin{array}{l}0.10 \pm 0.90 \\
P=0.9\end{array}$ & $\begin{array}{l}0.44 \pm 0.74 \\
P=0.6\end{array}$ \\
\hline$\Delta$ Plaque burden $(\%)$ & $\begin{array}{l}0.06 \pm 0.41 \\
P=0.9\end{array}$ & $\begin{array}{l}-0.01 \pm 0.46 \\
P=1.0\end{array}$ \\
\hline \multicolumn{3}{|l|}{ Plaque composition } \\
\hline$\Delta$ Fibrous volume $\left(\mathrm{mm}^{3}\right)$ & $\begin{array}{l}0.32 \pm 0.42 \\
P=0.5\end{array}$ & $\begin{array}{l}0.05 \pm 0.42 \\
P=0.9\end{array}$ \\
\hline$\Delta$ Fibrous volume $(\%)$ & $\begin{array}{l}-0.23 \pm 0.37 \\
P=0.5\end{array}$ & $\begin{array}{l}-0.63 \pm 0.38 \\
P=0.1\end{array}$ \\
\hline$\Delta$ Fibro-lipidic volume $\left(\mathrm{mm}^{3}\right)$ & $\begin{array}{l}-0.01 \pm 0.19 \\
P=1.0\end{array}$ & $\begin{array}{l}0.08 \pm 0.15 \\
P=0.6\end{array}$ \\
\hline$\Delta$ Fibro-lipidic volume $(\%)$ & $\begin{array}{l}-0.35 \pm 0.22 \\
P=0.1\end{array}$ & $\begin{array}{l}-0.03 \pm 0.22 \\
\mathrm{P}=0.9\end{array}$ \\
\hline$\Delta$ Necrotic core volume $\left(\mathrm{mm}^{3}\right)$ & $\begin{array}{l}0.28 \pm 0.16 \\
P=0.1\end{array}$ & $\begin{array}{l}0.15 \pm 0.16 \\
P=0.4\end{array}$ \\
\hline$\Delta$ Necrotic core volume $(\%)$ & $\begin{array}{l}0.34 \pm 0.17 \\
P=0.1\end{array}$ & $\begin{array}{l}0.03 \pm 0.24 \\
P=0.9\end{array}$ \\
\hline$\Delta$ Calcium volume $\left(\mathrm{mm}^{3}\right)$ & $\begin{array}{l}0.09 \pm 0.08 \\
P=0.3\end{array}$ & $\begin{array}{l}0.14 \pm 0.08 \\
P=0.1\end{array}$ \\
\hline$\Delta$ Calcium volume $(\%)$ & $\begin{array}{l}0.24 \pm 0.43 \\
P=0.6\end{array}$ & $\begin{array}{l}0.62 \pm 0.37 \\
P=0.1\end{array}$ \\
\hline
\end{tabular}

Reduced number of analyzed image frames versus measurement variability

As current systems for RF-IVUS analysis still require some manual editing of the automatically detected contours, a reduction in number of image frames used for generation of volumetric data is likely to reduce workload and time of analysis. In addition, the data of the present study suggest that an increase in pullback speed to $1.0 \mathrm{~mm} / \mathrm{s}$ and analysis of every frame within target lesions may possibly equalize an IVUS pullback speed of $0.5 \mathrm{~mm} / \mathrm{s}$ and analysis of every other frame. Such an increase in pullback speed could be advantageous, as it may increase patient comfort by shortening the duration of lumen obstruction in target lesions prior to PCI. On the other hand, we cannot exclude that a higher pullback speed may perhaps lead to more 'jumps' of the IVUS catheter in heavily calcified or tortuous vessel segments, which could increase measurement variability.

We previously addressed the issue of reducing the number of image frames for generation of volumetric data in coronary segments with a substantially lower level of atherosclerotic disease [19]. In those segments with mild-to-moderate atherosclerosis, representing a stage of disease typically examined in trials that address the progression or regression of coronary atherosclerosis, a reduced number of image frames saved analysis time, but increased the variability of volumetric RF-IVUS measurements above the level 

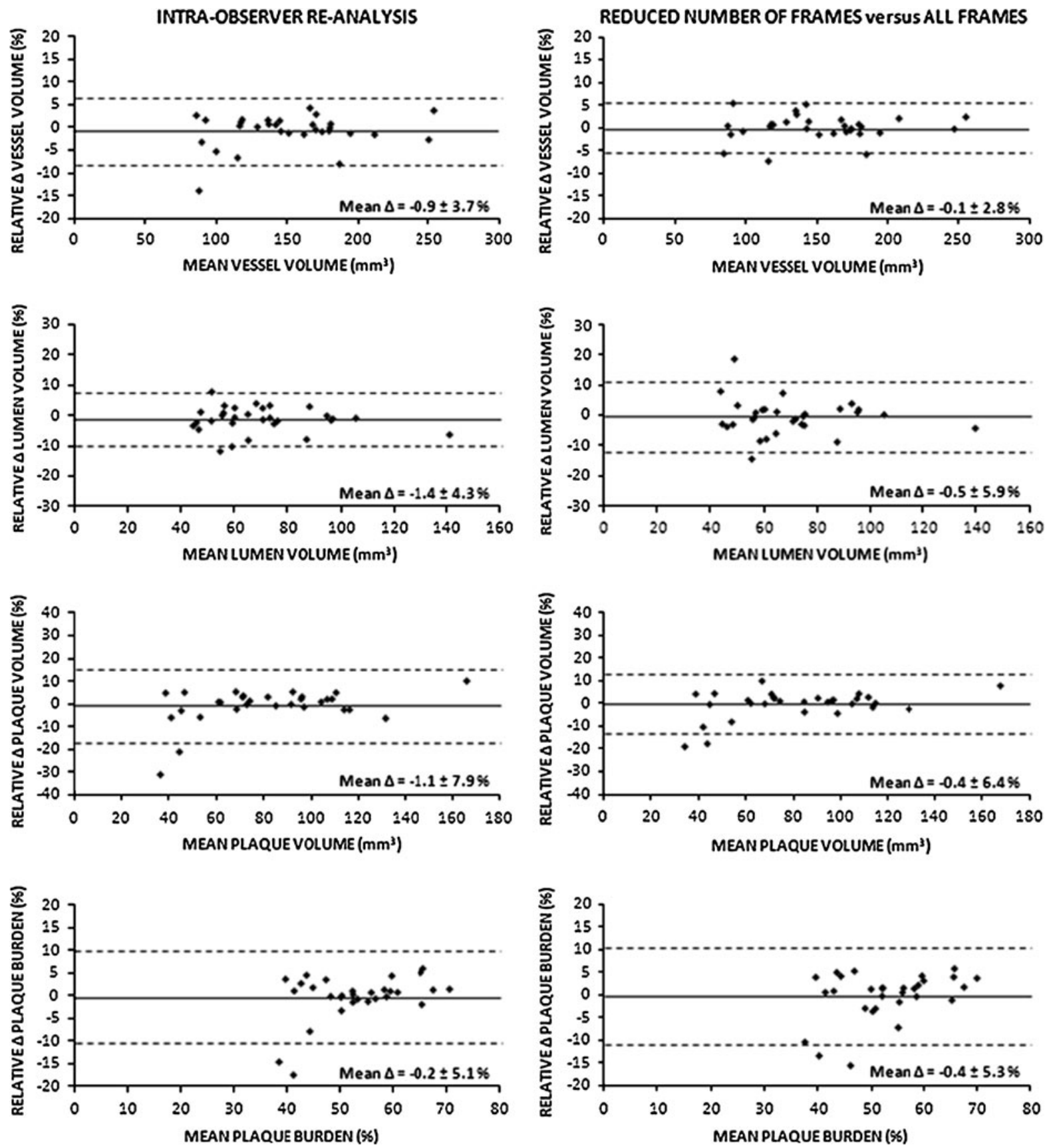

Fig. 2 Agreement of repeated RF-IVUS measurements of volumetric geometrical data. Agreement for intra-observer comparisons (re-analysis based on all image frames; Analysis I versus Analysis II) and comparison of reduced number of

frames versus analysis of all frames (Analysis I versus Analysis III). Mean difference $(\Delta)$ did not differ significantly between both comparisons

Our present study in more advanced coronary atherosclerosis (in target lesions prior to PCI) demonstrates - on the contrary - that a reduced number of 

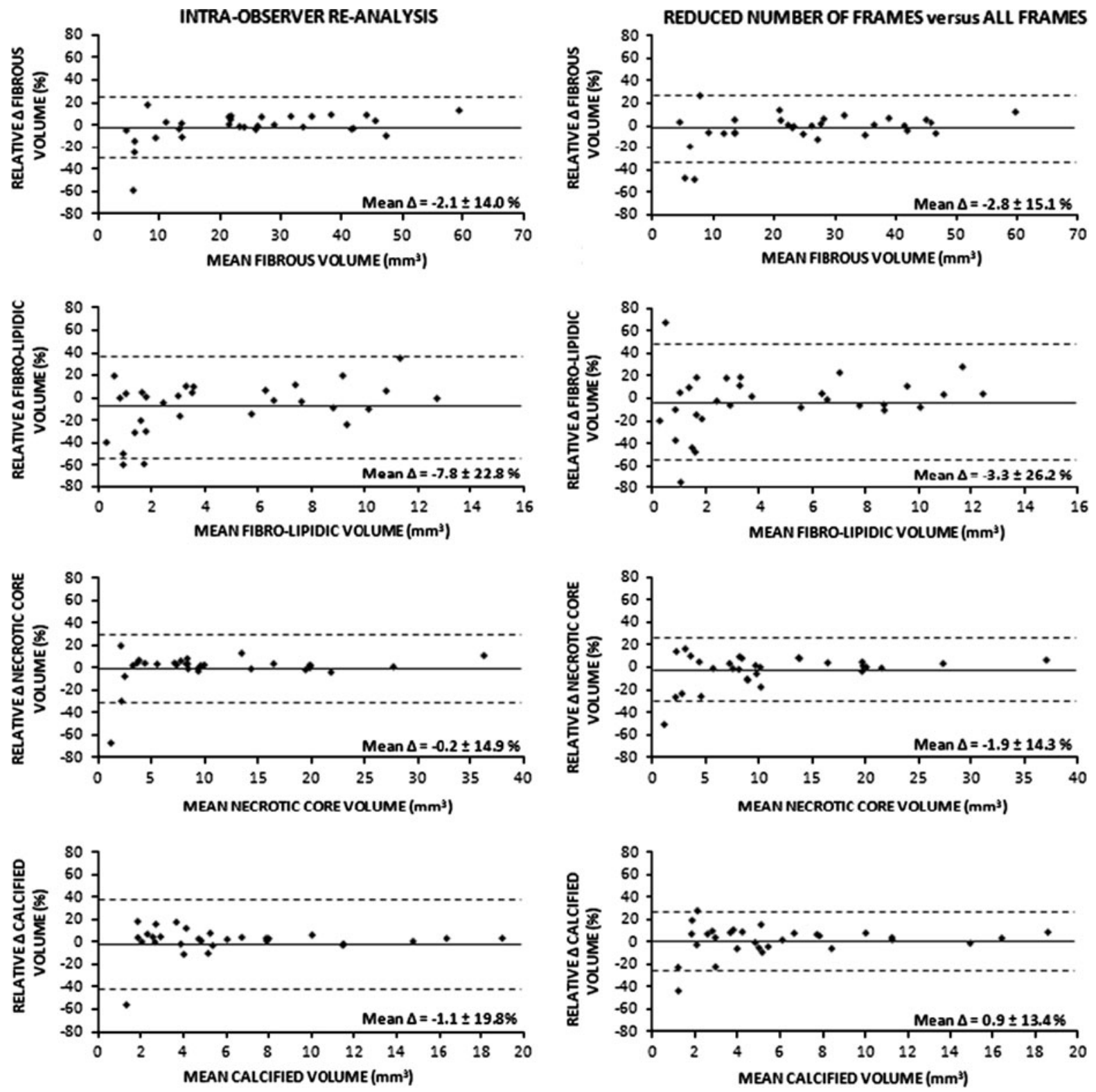

Fig. 3 Agreement of repeated RF-IVUS measurements of volumetric compositional data. Agreement for intra-observer comparisons (re-analysis based on all image frames; Analysis I versus Analysis II) and comparison of reduced number of

image frames did not increase the variability of volumetric RF-IVUS measurements above the level of the intra-observer variability. This may be partly explained by the fact that a mild absolute difference between repeatedly detected contours may affect volumetric data in larger plaques to a lower extent compared to the smaller plaques studied in our previous report [19]. In addition, the assessment of

frames versus analysis of all frames (Analysis I versus Analysis III). Mean difference $(\Delta)$ did not differ significantly between both comparisons

significant coronary lesions is inherently associated with a somewhat lower IVUS image quality because of reduced flow due to luminal obstruction by the IVUS catheter, more direct contact between IVUS catheter and plaque, and the presence of somewhat more calcium compared to segments with mild-to-moderate disease that may explain the higher intra-observer variability [(standard deviation of mean difference 
divided by mean measurement) $\times 100$ ]: $<22 \%$ in present study versus $<7 \%$ in mild disease [19].

Within long IVUS segments, it could be interesting to make a distinction between sub-segments that can be analyzed on an every-other-frame basis versus sub-segments that are better analyzed frame-byframe. The findings of the present study do not allow such distinction as the 20-mm-long segments analyzed contained not only the site of maximum lumen narrowing but also the shoulders of the lesions up tot the reference segments which means that there was a considerable variation in plaque burden within segments. Further insights may be obtained from future studies addressing relatively short, homogeneously diseased coronary segments with broad spectrum of lumen narrowing and plaque burden between individual segments.

Does it make sense to measure plaque composition in target lesions of PCI?

Volumetric assessment of plaque composition-in particular of necrotic core volume-prior to PCI may provide interesting information with prognostic implications. Necrotic core volume which shows a strong relation with plaque size may be an important factor for the outcome of PCI [26]. For instance, the presence of a relatively large necrotic core may lead to an increased myocardial injury due to peri-interventional microembolization during stent implantation [11, 27]. Hong et al. [15] demonstrated that the (absolute) necrotic core volume was the only independent predictor of significant troponin elevation post-PCI both in patients with stable and unstable angina. In addition, volumetric plaque composition seems to be related to the development of a no-reflow phenomenon after stent deployment in patients with acute coronary syndrome $[14,28]$. As a consequence, pre-PCI volumetric RF-IVUS assessment may have the potential to identify lesions at particularly high risk for PCI complications that may help to tailor such procedures.

However, RF-IVUS image analysis depends on accurate contour detection that is still quite time consuming and that limits its use for decision-making during routine PCI procedures. The present study demonstrates that the analysis of every second RF-IVUS frame may be an option to reduce time of analysis without introducing major deviations from the results of the full analysis or substantially increasing measurement variability.

\section{Limitations}

In the present study, IVUS analyses were performed in an offline setting in target lesions prior to PCI; therefore our findings cannot be extrapolated to RF-IVUS reproducibility studies in an online setting or in segments with mild atherosclerosis [19]. Similar to other studies that assessed the reproducibility of (RF-)IVUS, we did not include very tortuous and severely calcified vessels that could have led to a nonuniform pullback speed and/or inability to reliably detect the external vessel contour [17, 19-21]. Accordingly, measurement reproducibility could be lower in unselected cases with extensive calcification or vessel tortuousity. The number of coronary segments and the segment length studied was limited, but similar to previous studies on IVUS reproducibility [4, 17, 19-21]. We did not address potential variability between IVUS catheters, pullbacks, different pullback speeds, or pullback devices because our study was focused on the assessment of reducing the number of image frames for volumetric RF-IVUS analyses.

\section{Conclusions}

In target lesions prior to PCI, offline volumetric RFIVUS analyses can be performed using a reduced number of image frames (every second frame). This reduces the time of analysis without substantially increasing measurement variability.

Acknowledgments The authors thank Prof. Job van der Palen (Department of Research Methodology, Measurement and Data Analysis at the University of Twente in Enschede) for statistical advice. The study was investigator-initiated; it was not funded.

Conflict of interest Dr. G. S. Mintz is a consultant to Volcano corp. Other authors have no potential conflict of interest.

Open Access This article is distributed under the terms of the Creative Commons Attribution Noncommercial License which permits any noncommercial use, distribution, and reproduction in any medium, provided the original author(s) and source are credited. 


\section{References}

1. Bruining N, Verheye S, Knaapen M, Somers P, Roelandt JR, Regar E, Heller I, de Winter S, Ligthart J, Van Langenhove G, de Feijter PJ, Serruys PW, Hamers R (2007) Three-dimensional and quantitative analysis of atherosclerotic plaque composition by automated differential echogenicity. Catheter Cardiovasc Interv 70(7):968-978

2. Di Mario C, Gorge G, Peters R, Kearney P, Pinto F, Hausmann D, von Birgelen C, Colombo A, Mudra H, Roelandt J, Erbel R (1998) Clinical application and image interpretation in intracoronary ultrasound. Study group on intracoronary imaging of the working group of coronary circulation and of the subgroup on intravascular ultrasound of the working group of echocardiography of the European society of cardiology. Eur Heart J 19(2):207-229

3. Mintz GS, Nissen SE, Anderson WD, Bailey SR, Erbel R, Fitzgerald PJ, Pinto FJ, Rosenfield K, Siegel RJ, Tuzcu EM, Yock PG (2001) American college of cardiology clinical expert consensus document on standards for acquisition, measurement and reporting of intravascular ultrasound studies (IVUS). A report of the American college of cardiology task force on clinical expert consensus documents. J Am Coll Cardiol 37(5):1478-1492

4. Garcia-Garcia HM, Mintz GS, Lerman A, Vince DG, Margolis MP, van Es GA, Morel MA, Nair A, Virmani R, Burke AP, Stone GW, Serruys PW (2009) Tissue characterisation using intravascular radiofrequency data analysis: recommendations for asquisition, analysis, interpretation and reporting. Eurointervention 5(2):177-189

5. König A, Klauss V (2007) Virtual histology. Heart 93(8): 977-982

6. Nair A, Margolis MP, Kuban BD, Vince DG (2007) Automated coronary plaque characterisation with intravascular ultrasound backscatter: ex vitro validation. Eurointervention 3(1):113-120

7. Nair A, Kuban BD, Tuzcu EM, Schoenhagen P, Nissen SE, Vince DG (2002) Coronary plaque classification with intravascular ultrasound radiofrequency data analysis. Circulation 106(17):2200-2206

8. Nasu K, Tsuchikane E, Katoh O, Vince DG, Virmani R, Surmely JF, Murata A, Takeda Y, Ito T, Ehara M, Matsubara T, Terashima M, Suzuki T (2006) Accuracy of in vivo coronary plaque morphology assessment: a validation study of in vivo virtual histology compared with in vitro histopathology. J Am Coll Cardiol 47(12):2405-2412

9. van Herck J, de Meyer G, Ennekens G, Van Herck P, Herman A, Vrints C (2009) Validation of in vivo plaque characterisation by virtual histology in a rabbit model of atherosclerosis. EuroIntervention 5(1):149-156

10. Serruys PW, Garcia-Garcia HM, Buszman P, Erne P, Verheye S, Aschermann M, Duckers H, Bleie O, Dudek D, Botker HE, von Birgelen C, D'Amico D, Hutchinson T, Zambanini A, Mastik F, van Es GA, van der Steen AF, Vince DG, Ganz P, Hamm CW, Wijns W, Zalewski A (2008) Effects of the direct lipoprotein-associated phospholipase $\mathrm{A}(2)$ inhibitor darapladib on human coronary atherosclerotic plaque. Circulation 118(11):1172-1182

11. Böse D, von Birgelen C, Zhou XY, Schmermund A, Philipp S, Sack S, Konorza T, Mohlenkamp S, Leineweber
K, Kleinbongard P, Wijns W, Heusch G, Erbel R (2008) Impact of atherosclerotic plaque composition on coronary microembolization during percutaneous coronary interventions. Basic Res Cardiol 103(6):587-597

12. Garcia-Garcia HM, Shen Z, Piazza N (2009) Study of restenosis in drug eluting stents: new insights from greyscale intravascular ultrasound and virtual histology. EuroIntervention 5(Suppl D):D84-D92

13. Garcia-Garcia HM, Gonzalo N, Kukreja N, Alfonso F (2008) Greyscale intravascular ultrasound and IVUSradiofrequency tissue characterisation to improve understanding of the mechanisms of coronary stent thrombosis in drug-eluting stents. EuroIntervention 4(Suppl C): C33-C38

14. Hong YJ, Jeong MH, Choi YH, Ko JS, Lee MG, Kang WY, Lee SE, Kim SH, Park KH, Sim DS, Yoon NS, Youn HJ, Kim KH, Park HW, Kim JH, Ahn Y, Cho JG, Park JC, Kang JC (2009) Impact of plaque components on no-reflow phenomenon after stent deployment in patients with acute coronary syndrome: a virtual histology-intravascular ultrasound analysis. Eur Heart J doi: 10.1093/eurheartj/ehp034

15. Hong YJ, Mintz GS, Kim SW, Lee SY, Okabe T, Pichard AD, Satler LF, Waksman R, Kent KM, Suddath WO, Weissman NJ (2009) Impact of plaque composition on cardiac troponin elevation after percutaneous coronary intervention: an ultrasound analysis. JACC Cardiovasc Imaging 2(4):458-468

16. Mehta SK, McCrary JR, Frutkin AD, Dolla WJ, Marso SP (2007) Intravascular ultrasound radiofrequency analysis of coronary atherosclerosis: an emerging technology for the assessment of vulnerable plaque. Eur Heart J 28(11): 1283-1288

17. Hartmann M, Mattern ES, Huisman J, van Houwelingen GK, de Man FH, Stoel MG, Danse PW, Louwerenburg HW, von Birgelen C (2009) Reproducibility of volumetric intravascular ultrasound radiofrequency-based analysis of coronary plaque composition in vivo. Int $\mathbf{J}$ Cardiovasc Imaging 25(1):13-23

18. Huisman J, Egede R, Rdzanek A, Böse D, Erbel R, Kochman J, Jensen LO, van de Palen J, Hartmann M, Mintz GS, von Birgelen C (2010) Between-centre reproducibility of volumetric intravascular ultrasound radiofrequency-based analyses in mild-to-moderate coronary atherosclerosis: an international multicentre study. Eurointervention 5:925-931

19. Huisman J, Hartmann M, Mattern ESK, Mintz GS, Basalus MWZ, van Houwelingen GK, Verhorst PMJ, von Birgelen C (2010) Impact of analyzing less image frames per segment for radiofrequency-based volumetric intravascular ultrasound measurements in mild-to-moderate coronary atherosclerosis. Int J Cardiovasc Imaging 26(5):487-497

20. Prasad A, Cipher DJ, Prasad A, Mohandas A, Roesle M, Brilakis ES, Banerjee S (2008) Reproducibility of intravascular ultrasound virtual histology analysis. Cardiovasc Revasc Med 9(2):71-77

21. Rodriguez-Granillo GA, Vaina S, Garcia-Garcia HM, Valgimigli M, Duckers E, van Geuns RJ, Regar E, van der Giessen WJ, Bressers M, Goedhart D, Morel MA, de Feyter PJ, Serruys PW (2006) Reproducibility of intravascular ultrasound radiofrequency data analysis: 
implications for the design of longitudinal studies. Int $\mathbf{J}$ Cardiovasc Imaging 22(5):621-631

22. Bruining N, von Birgelen C, de Feyter PJ, Ligthart J, Li W, Serruys PW, Roelandt JR (1998) ECG-gated versus nongated three-dimensional intracoronary ultrasound analysis: implications for volumetric measurements. Cathet Cardiovasc Diagn 43(3):254-260

23. Bland JM, Altman DG (1986) Statistical methods for assessing agreement between two methods of clinical measurement. Lancet 1(8476):307-310

24. von Birgelen C, de Vrey EA, Mintz GS, Nicosia A, Bruining N, Li W, Slager CJ, Roelandt JR, Serruys PW, de Feyter PJ (1997) ECG-gated three-dimensional intravascular ultrasound: feasibility and reproducibility of the automated analysis of coronary lumen and atherosclerotic plaque dimensions in humans. Circulation 96(9):2944-2952

25. von Birgelen C, Slager CJ, Di Mario C, de Feyter PJ, Serruys PW (1995) Volumetric intracoronary ultrasound: a new maximum confidence approach for the quantitative assessment of progression-regression of atherosclerosis? Atherosclerosis 118(Suppl):S103-S113

26. von Birgelen C, Huisman J, Hartmann M (2010) Is size really all that matters? Remarks on size and necrotic core content of atherosclerotic plaques. Int J Cardiovasc Imaging 26(2): 173-176

27. Kawaguchi R, Oshima S, Jingu M, Tsurugaya H, Toyama T, Hoshizaki H, Taniguchi K (2007) Usefulness of virtual histology intravascular ultrasound to predict distal embolization for ST-segment elevation myocardial infarction. J Am Coll Cardiol 50(17):1641-1646

28. Nakamura T, Kubo N, Ako J, Momomura S (2007) Angiographic no-reflow phenomenon and plaque characteristics by virtual histology intravascular ultrasound in patients with acute myocardial infarction. J Interv Cardiol 20(5):335-339 